\title{
Implications of Patent Pools on Innovation Regarding Antiretrovirals ${ }^{\S}$
}

\author{
Eric Noehrenberg*
}

\author{
Noehrenberg International Policy Consultancy, Geneva, Switzerland
}

\begin{abstract}
Patent pools have been promoted as an innovative means of promoting the production of fixed-dose combination antiretroviral medicines (ARVs), which can be particularly appropriate for resource-poor settings. An important question, however, is what are the implications of patent pools on innovation for creating new and improved antiretrovirals. Indeed, given the continuing mutation of HIV and growing resistance to existing treatments, continued innovation in ARV development is vital for addressing these challenges. Would patent pools be a hindrance or rather a stimulus for further innovation? This question is particularly relevant in light of UNITAID's initiative to create a patent pool for ARV development, focusing on pediatric formulations and new combinations, by the end of 2009 .

In this article, the author argues that a voluntary and well-designed patent pool, involving both innovative and generic manufacturers, focused on developing fixed-dose combinations for resource-poor markets with the greatest need, could actually stimulate increased innovation to meet these needs. Indeed, by bringing together the major ARV producers worldwide to collaborate on developing products which will meet the needs of the poorest, an ARV patent pool could create significant public health benefits. UNITAID has taken the lead in designing and implementing such a pool and UNITAID's experience will have important lessons for policy-makers in the future.
\end{abstract}

\section{INTRODUCTION}

Patent pools have been promoted as an innovative means of promoting the production of fixed-dose combination antiretroviral medicines (ARVs), which can be particularly appropriate for resource-poor settings [1]. As other authors in this issue will have presented, the use of a patent pool could be used to overcome possible patent-based barriers to combining products from a variety of producers.

An important additional question, however, is what are the implications of patent pools on innovation for creating new and improved antiretrovirals. Indeed, given the continuing mutation of HIV and growing resistance to existing treatments, continued innovation in ARV development is vital for addressing these challenges. Would patent pools be a hindrance or rather a stimulus for further innovation? This question is particularly relevant in light of UNITAID's initiative to create a patent pool for ARV development, focusing on pediatric formulations and new combinations, by the end of 2009 .

\section{CRITIQUES OF PATENT POOLS' IMPACT ON INNOVATION}

The answer to the above question depends greatly upon how the proposed patent pool would be organized and how it would be set up. A major critique of proposals to include current and future ARVs in patent pools is the concern that such inclusion may actually dis-incentivize innovation in

*Address correspondence to this author at the Noehrenberg International Policy Consultancy, Geneva, Switzerland; E-mail: nipcpres@live.com

${ }^{\S}$ Please note that the opinions expressed in this article are purely Dr. Noehrenberg's own personal opinions and should not be seen as reflecting the positions of Dr. Noehrenberg's present or past employers.
ARVs. According to this argument, a patent pool would act as a group compulsory license, depriving patent-holders of their rights in growing markets around the world and giving the fruits of their R\&D investment to copiers for little compensation, if any. In such a system, the fear would be that any new ARVs would be automatically included in the patent pool, thus reducing the possibility for the innovator to recoup his or her R\&D investment for these medicines. Furthermore, some observers have expressed concerns regarding the quality of combination products which have not been approved by major, industrialized-country regulatory authorities and, by implication, have indicated that patent pools would lead to lower-quality products being developed by copy companies without sufficient regulatory oversight.

While the above points are indeed important concerns, a well-designed patent pool could address them and, in doing so, stimulate further innovation by bringing new partners into the global R\&D effort to produce new and improved ARVs.

With regard to the "group compulsory license" argument, a voluntary patent pool would be the ideal solution. If innovators could be sufficiently convinced of the benefits of contributing their patents into the pool, that would promote voluntary collaboration in ARV development. For example, if the designers of a patent pool could show the innovators how combining the products can produce a superior product (in terms of efficacy, adherence to treatment regimens, lower patient cost, possibly improved production capacity, etc.), that could be helpful in convincing them to include their patents in a pool, particularly if that pool is limited in terms of geographic scope. Furthermore, governments and/or international procurement agencies could provide incentives for participation in the patent pool. Such incentives could 
include: advance market commitments to procure large volumes of medicines developed via the patent pool; allowing the procurement of drugs developed via the patent pool at a certain premium; or other financial or market-based incentives.

The geographic scope is important in light of the second critique concerning patent pools, that such pools could reduce incentives for further innovation. The countries which are most affected by the AIDS pandemic are low-income countries in sub-Saharan Africa. Many of the leading innovating producers of ARVs have publicly stated that they are offering their products to these countries at a "at cost" or even "below cost" basis. If this is indeed the case, then there would be no "lost" financial incentives if alternative producers also were to manufacture ARVs for these markets using the patent pool. Furthermore, if products are indeed being offered at a "below cost" basis, it should be in the innovator's interest to involve other partners in order to share the burden of the cost of production and distribution to reach these "below cost" markets.

With respect to the issue of drug quality of ARVs developed via a patent pool, the World Health Organization (WHO) is already providing a reliable and objective system for approving such drugs through WHO's "Prequalification System" (PQS) [2]. By using experienced experts from internationally-recognized drug regulatory authorities, WHO's PQS helps to assure that the products reviewed and approved by them meet international quality standards, giving important guidance to national procurement authorities so that these authorities can avoid producers of inferior or even counterfeit quality. WHO's PQS has even "de-listed" producers who could not continue to meet PQS' quality standards, which is a further evidence of the PQS' objectivity and reliability [2].

Some national authorities will also review and approve products which, for patent reasons, cannot be sold in their national markets. The US FDA reviews drugs for use abroad via the US PEPFAR program, for example. Also, Health Canada has reviewed and approved fixed-dose combination antiretroviral products manufactured in Canada for export to Rwanda under Canada's export compulsory license regime (called "C-9" after the Canadian legislation authorizing such production) [3]. Thus, there are opportunities for UNITAID and, in the future, other funding and procurement authorities, to find ways of ensuring that the fixed-dose ARVs produced via a patent pool system can be quality-assured by objective, internationally-recognized bodies [4].

\section{POSSIBLE POSITIVE IMPACT OF PATENT POOLS FOR INNOVATION}

As noted above, a well-designed patent pool needs not have a negative impact on innovation for new and improved ARVs. Furthermore, if set up correctly, a patent pool could even promote greater innovation in ARV development to meet patients' needs, particularly for affected populations in resource-poor settings most impacted by the AIDS pandemic.

Such improved innovation is particularly valid for the development of fixed-dose combination products for resource-poor settings, including for pediatric formulations [5]. While a few innovative pharmaceutical companies have developed fixed-dose combination products (some in collaboration with other innovative firms, some using owncompany products only), not all valid combinations of ARVs recommended by WHO for use in resource-poor settings are available in fixed-dose format. There are certainly technical challenges to producing high-quality and effective fixed dose combinations of ARVs, but patent issues can also play a role in slowing the development of fixed-dose combinations involving products from different patent-holders. If the relevant patents are included voluntarily into a patent pool, however, than other pharmaceutical companies can draw upon them to find innovative and possibly more effective ways to combine them in a fixed-dose format most appropriate for resource-poor settings.

Indeed, to make a patent pool most effectively promote innovation in ARV development, the patents of leading generic firms who are making fixed-dose combination products should also be voluntarily included in the pool. These product and process patents from generic producers can be very important in stimulating not only new combinations of products, but also in creating improved methods of combining and manufacturing fixed-dose combination products. By expanding the pool to include generics as well as innovative pharmaceutical companies, there will be greater possibilities for effective collaboration and more creative research in ARV innovation.

\section{CRITERIA FOR A PATENT POOL FOR ARVS}

- $\quad$ The pool must be voluntary in nature. Compulsory inclusion of ARV patents in a patent pool could have a chilling effect on future innovation.

- Incentives for voluntary participation can be important. For example, major national or international procurement agencies could give significant preferences to purchasing ARV products developed via a patent pool, such as granting a higher price or pledging guarantees to purchase large volumes of such products via advance marketing commitments.

- In line with patent pools in other industries, only those companies contributing to the pool should be allowed to draw on the patents in the pool. This would be an incentive for companies to join the pool, as only members would be able to benefit from the expanded access to other companies's patents. Such a requirement would not exclude generic companies, as generic producers of fixed-dose combinations could contribute to the pool their process patents relevant for manufacturing fixed-dose combination products.

- The patent pool should focus on developing fixeddose combinations for resource-poor settings most impacted by the AIDS pandemic. Such a focus would address the greatest global need in terms of ARV care. Furthermore, focusing on such poor markets will allay the concerns of some innovative companies that participation in the patent pool could hurt their financial interests guarded by patents. Given that 
ARV supply to the poorest countries is given at a "at cost" or "below cost" basis, there should be no additional financial loss to companies if they participate in a patent pool. Indeed, by working more collaboratively with others, including generics, there could be less of a financial burden on the innovative companies to supply such resource-poor markets. A focus on resource-poor countries should also be linked with ensuring that the products are not unduly diverted, so that the intended recipients can indeed benefit from these products.

- Even with such a focus on the needs of the poorest, patients in richer and mid-income countries can also benefit from the increased innovation arising from an effective patent pool, as the innovative combination products arising from such a pool could become eventually available in the mid-income and other markets.

- In order to ensure credibility with innovative and generic companies, as well as with other partners, the patent pool needs to be organized and managed by a reputable international organization. UNITAID is taking the lead in this effort and, given UNITAID's unique structure and sustainable financing mechanism, is most likely to make a patent pool for ARVs a success [6]. Thus, UNITAID's experience will be an important guide in the development of an ARV patent pool for innovation.

\section{CONCLUSIONS}

The concept of a patent pool for antiretrovirals has been subject of much discussion in international health policy circles for several years. Strong concerns have been expressed regarding the possible impact of a patent pool on innovation in ARV development. However, a voluntary and well-designed patent pool, involving both innovative and generic manufacturers, focused on developing fixed-dose combinations for resource-poor markets with the greatest need, could actually stimulate increased innovation to meet these needs. Indeed, by bringing together the major ARV producers worldwide to collaborate on developing products which will meet the needs of the poorest, an ARV patent pool could create significant public health benefits.

UNITAID has taken the lead in designing and implementing such a pool and UNITAID's experience will have important lessons for policy-makers in the future.

\section{REFERENCES}

[1] 't Hoen E, von Schoen-Angerer T. A patent pool for medicines. TheWorldToday.org 2009: 30-31. Available at: http://www.msf access.org/resources/key-publications/key-publication-detail/?tx_tt news\%5Btt_news\%5D=1522\&cHash=79c9cf6960 (accessed July 2009).

[2] Prequalification programme, a United Nations Programme managed by WHO. Available from: http://apps.who.int/prequal/ pq_main.htm (accessed July 2009).

[3] Canadian WTO notification clears path for Rwanda to import generic HIV/AIDS drug. ICTSD Bridges (10 October 2007) vol. 11 n. 34. Available from: http:/www.ictsd.org/weekly/07-10-10/story 4.htm (accessed July 2009).

[4] UNITAID patent pool at Mexico City conference (6 August 2008, Knowledge Ecology International-KEI). Available from: http://ww w.keionline.org/index.php?option $=$ com_jd-wp\&Itemid $=39 \& p=135$

[5] Sixty-first World Health Assembly 24 May 2008: Global strategy and plan of action on public health, innovation and intellectual property. Available from: http://www.who.int/gb/ebwha/pdf_files/ A61/A61 R21-en.pdf

[6] Bermudez J. Access to medicines and IPR: UNITAID moving towards a patent pool? UNITAID second consultative forum (Dakar, Senegal, 6 December 2008). Available from : http://www. unitaid.eu/index.php/en/NEWS/UNITAID-Consultative-Forum-2008. html 